\title{
PROPRIEDADES QUÍMICAS E FERTILIDADE DOS SOLOS AGRÍCOLAS DE ADAMANTINA-SP
}

\author{
NASSER, Maurício Dominguez ${ }^{1}$ \\ FURLANETO, Fernanda de Paiva Badiz ${ }^{2}$ \\ TAVARES, Mateus Batista ${ }^{3}$ \\ ZONTA, Augusto ${ }^{4}$ \\ JACON, Camila Paula Rossetto Pescatori ${ }^{5}$ \\ VITORINO, Rodrigo Aparecido ${ }^{6}$
}

\begin{abstract}
Recebido em: 2021.01.06 Aprovado em: 2021.04.29 ISSUE DOI: 10.3738/1982.2278.3889
RESUMO: A fertilidade do solo se destaca como um dos fatores que influenciam no rendimento da cultura. Diante do exposto objetivou-se avaliar as propriedades químicas e fertilidade dos solos agrícolas em Adamantina-SP. Foram avaliadas 114 análises de $\mathrm{pH}\left(\mathrm{CaCl}_{2}\right)$, matéria orgânica $\left(\mathrm{g} \mathrm{dm}^{-3}\right)$, P resina $\left(\mathrm{mg} \mathrm{dm}^{-3}\right), \mathrm{K}, \mathrm{Ca}, \mathrm{Mg}$, capacidade de troca catiônica $\left(\right.$ mmolc $\left.\mathrm{dm}^{-3}\right)$ e saturação de bases $(\mathrm{V} \%) ; 58$ análises de $\mathrm{S}\left(\mathrm{mg} \mathrm{dm}^{-3}\right)$ e 59 de micronutrientes: Fe, Mn, Zn, $\mathrm{Cu}$ e $\mathrm{B}\left(\mathrm{mg} \mathrm{dm}^{-3}\right)$. Os resultados foram tabulados e organizados em gráficos e a distribuição dos valores para cada característica expressos em porcentagem (\%). Calculou-se, também, a moda ou valor de maior frequência. Concluiuse que os solos de Adamantina-SP, de modo geral, recebem calagem, fertilizantes a base de macronutrientes e, em alguns casos, adubo orgânico de baixa permanência no solo, que influenciam diretamente na capacidade de troca catiônica e disponibilidade de $\mathrm{P}, \mathrm{S}$ e B que apresentaram níveis reduzidos nos solos avaliados no estudo.
\end{abstract}

Palavras-chave: Adubação. Correção de solo. Fitotecnia. Sistemas de produção.

\section{CHEMICAL PROPERTIES AND FERTILITY OF AGRICULTURAL SOILS IN ADAMANTINA-SP}

SUMMARY: Soil fertility stands out as one of the factors that influence crop yield. Given the above, the objective was to evaluate the chemical properties and fertility of agricultural soils in Adamantina-SP. 114 analyzes of $\mathrm{pH}$ $\left(\mathrm{CaCl}_{2}\right)$, organic matter $\left(\mathrm{g} \mathrm{dm}^{-3}\right)$, $\mathrm{P}$ resin $\left(\mathrm{mg} \mathrm{dm}^{-3}\right), \mathrm{K}, \mathrm{Ca}, \mathrm{Mg}$, cation exchange capacity $\left(\mathrm{mmolc} \mathrm{dm}^{-3}\right)$ and base saturation (V\%); 58 analyzes of $\mathrm{S}\left(\mathrm{mg} \mathrm{dm}^{-3}\right.$ ) and 59 of micronutrients: $\mathrm{Fe}, \mathrm{Mn}, \mathrm{Zn}, \mathrm{Cu}$ and $\mathrm{B}\left(\mathrm{mg} \mathrm{dm}^{-3}\right)$. The results were tabulated and organized in graphs and the distribution of values for each characteristic expressed in percentage $(\%)$. The most frequent mode or value was also calculated. It was concluded that the soils of Adamantina-SP, in general, receive liming, macronutrient based fertilizers and, in some cases, low permanence organic fertilizer in the soil, which directly influence the cation exchange capacity and availability of P, S and B that showed reduced levels in the soils evaluated in the study.

Keywords: Fertilization. Soil correction. Fytotechnics. Production systems.

\footnotetext{
${ }^{1}$ ORCID ID https://orcid.org/0000-0002-4239-5958. Pesquisador Científico da Agência Paulista de Tecnologia dos Agronegócios (APTA) - Polo Regional Alta Paulista.

${ }^{2}$ ORCID ID https://orcid.org/0000-0003-0091-9968. Pesquisador Científico da Agência Paulista de Tecnologia dos Agronegócios (APTA) - Polo Regional Centro Oeste Paulista-Unidade de Pesquisa e Desenvolvimento de Marília.

${ }^{3}$ ORCID ID https://orcid.org/0000-0002-7204-6126. Engenheiro Agrônomo. Laboratório de Solos da Cooperativa Agrícola Mista de Adamantina (CAMDA).

${ }^{4}$ ORCID ID https://orcid.org/0000-0002-1702-4602. Pesquisador Científico da Agência Paulista de Tecnologia dos Agronegócios (APTA) - Polo Regional Alta Paulista.

${ }^{5}$ ORCID ID https://orcid.org/ 0000-0001-9670-1087. Engenheira Agrônoma. Pós-Doutoranda no Departamento de Solos e Recursos Ambientais da FCA/UNESP.

${ }^{6}$ ORCID ID https://orcid.org/0000-0002-2014-2378. Engenheiro Agrônomo. Auxiliar de Apoio à Pesquisa Cientifica da Agência Paulista de Tecnologia dos Agronegócios - Polo Regional Alta Paulista.
} 


\section{PROPIEDADES QUÍMICAS Y FERTILIDAD DE LOS SUELOS AGRÍCOLAS EN ADAMANTINA-SP}

RESUMEN: La fertilidad del suelo se destaca como uno de los factores que influyen en el rendimento. Dado lo anterior, el objetivo fue evaluar las propiedades químicas y la fertilidad de suelos agrícolas en Adamantina-SP. 114 análisis de $\mathrm{pH}\left(\mathrm{CaCl}_{2}\right)$, materia orgánica $\left(\mathrm{g} \mathrm{dm}^{-3}\right)$, resina $\mathrm{P}\left(\mathrm{mg} \mathrm{dm}^{-3}\right), \mathrm{K}, \mathrm{Ca}, \mathrm{Mg}$, capacidad de intercambio catiónico (mmolc dm-3) y saturación de bases (V \%); 58 análisis de S (mg dm-3) y 59 de micronutrientes: Fe, Mn, Zn, Cu y B (mg dm-3). Los resultados se tabularon y organizaron en gráficos y la distribución de valores para cada característica expresada en porcentaje (\%). También se calculó el modo o valor más frecuente. Se concluyó que los suelos de Adamantina-SP, en general, reciben encalado, fertilizantes a base de macronutrientes y, en algunos casos, fertilizante orgánico de baja permanencia en el suelo, que influyen directamente en la capacidad de intercambio catiónico y disponibilidad de P, S y B que presentaron niveles reducidos en los suelos evaluados en el estudio.

Palabras clave: Fertilización. Corrección de suelos. Fitotecnia. Sistemas de producción.

\section{INTRODUÇÃOO}

Os solos tropicais possuem limitações na produção de alimentos, uma vez que sofreram ações de fortes precipitações e alta radiação solar, resultando em perda de nutrientes por lixiviação, aumento da acidez e problemas de déficit hídrico, decorrentes de baixa infiltração. Dessa forma, a fertilidade do solo se destaca como um dos fatores que influenciam no rendimento da cultura (RODRIGUES et al., 2018).

Nesse contexto insere-se o extremo Oeste Paulista, particularmente o espigão divisor Peixe-Aguapeí, onde se localiza a Nova Alta Paulista, uma região que sofreu intensa exploração do solo ao longo de sua ocupação, tendo sua vegetação natural rapidamente extinta e substituída por culturas e pastagens (BOIN, 2000). A terra disponível, antes ocupada pelas áreas de mata nativa, conservavam umidade e grande disponibilidade de nutrientes provenientes da matéria orgânica decomposta, fatores que contribuíram temporariamente para o cultivo agrícola.

A mudança da vegetação natural para um sistema de exploração agropecuária sem manejo adequado provocou uma série de alterações nas propriedades do solo, como a perda da fertilidade natural, resultado da diminuição de matéria orgânica/atividade microbiana, e desestruturação das partículas do solo ocasionando consequente compactação (FREITAS et al., 2017).

Giaretta et al. (2019) apontam que a caracterização edáfica, com utilização frequente da análise de solo, é procedimento básico para nortear a tomada de decisão no gerenciamento agronômico das lavouras, garantindo manejo adequado dos solos, boa produtividade e contínua ciclagem dos nutrientes.

Diante das dificuldades da agricultura nas regiões tropicais, é primordial identificar as características de fertilidade dos solos, a fim de garantir manejo técnico adequado e uso 
racional de insumos. Diante do exposto, objetivou-se avaliar as propriedades químicas e fertilidade dos solos agrícolas de Adamantina-SP.

\section{MATERIAL E MÉTODO}

O trabalho foi realizado utilizando análises químicas de solo amostradas em diferentes propriedades rurais localizadas em Adamantina-SP. O município está inserido na Nova Alta Paulista, e tem significativa representação em termos de clima e solo da região. A agricultura predominante é do tipo familiar (LSPA, 2020). As amostras de solo foram oriundas de áreas de produção de frutas, hortaliças, pastagem, café, soja, milho, amendoim, mandioca e reflorestamento.

Os dados foram obtidos de laudos selecionados ao acaso de amostras de solo coletadas de 0 a $20 \mathrm{~cm}$ de profundidade, do banco de dados do Laboratório da Cooperativa Agrícola Mista de Adamantina (CAMDA), período de 2012 a 2020. Foram avaliadas 114 análises de $\mathrm{pH}\left(\mathrm{CaCl}_{2}\right)$, matéria orgânica $\left(\mathrm{g} \mathrm{dm}^{-3}\right)$, P resina $\left(\mathrm{mg} \mathrm{dm}^{-3}\right), \mathrm{K}, \mathrm{Ca}, \mathrm{Mg}$, capacidade de troca catiônica (mmolc $\left.\mathrm{dm}^{-3}\right)$ e saturação de bases (V\%); 58 análises de $\mathrm{S}\left(\mathrm{mg} \mathrm{dm}^{-3}\right)$ e 59 de micronutrientes: $\mathrm{Fe}, \mathrm{Mn}, \mathrm{Zn}, \mathrm{Cu}$ e B $\left(\mathrm{mg} \mathrm{dm}^{-3}\right)$.

As metodologias de análises seguiram normatização descrita em Teixeira et al. (2017). Nas interpretações de matéria orgânica (M.O.) e capacidade de troca catiônica (CTC) utilizaram-se faixas de teores descritas por Sobral et al. (2015). Os resultados foram tabulados e organizados em gráficos e a distribuição dos valores para cada característica expressos em porcentagem (\%). Calculou-se, também, a moda ou valor de maior frequência.

\section{RESULTADO E DISCUSSÃO}

Notou-se que $80 \%$ do $\mathrm{pH}$ está limitado até 5,5 (Figura 1) e que praticamente $20 \%$ atinge a faixa adequada para maioria das culturas (de 5,5 a 6,5), ou seja, quando os nutrientes estão mais disponíveis para planta (PREZOTTI; GUARÇONI, 2013). O valor da moda de 4,6 caracteriza valor baixo para $\mathrm{pH}$, inferindo solos com tendência para acidez e que demandam correção para manejo adequado da fertilidade. 
Figura 1. Faixa de teores e respectiva porcentagem de $\mathrm{pH}, \mathrm{CTC}$ e saturação por bases em solos agrícolas de Adamantina-SP.
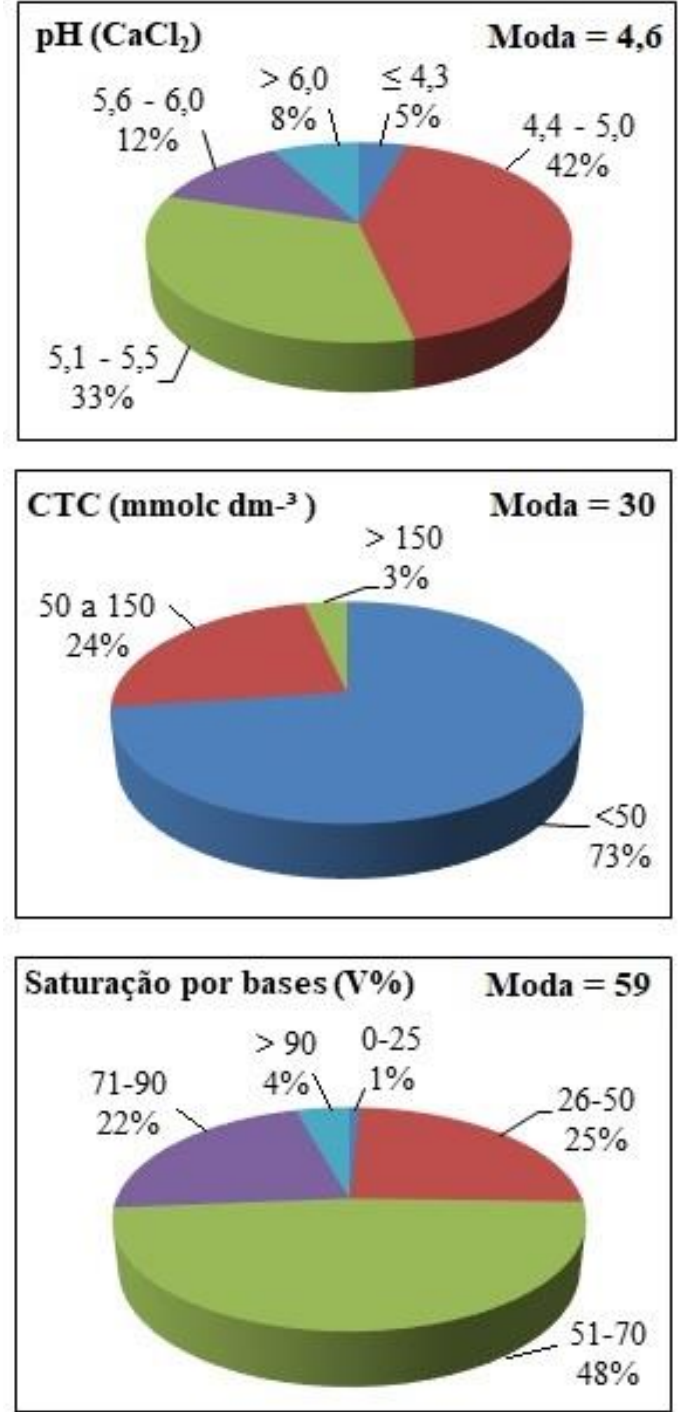

Fonte: Elaborada pelos autores, 2021.

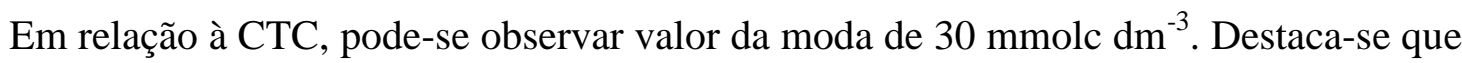
mais de $70 \%$ está abaixo de $50 \mathrm{mmolc} \mathrm{dm}^{-3}$ (Figura 1). Esse valor indica que os solos têm baixo teor de argila e predominância da caulinita na sua composição mineral, sendo rico em óxidos de alumínio e ferro, bem como baixa concentração de sílica. Desta forma, ressalta-se a importância de parcelar nutrientes de fácil mobilidade no solo como nitrogênio e potássio, que podem ser mais lixiviados (VIEIRA et al., 2020).

Ressalta-se que a CTC está relacionada a solos de baixa matéria orgânica associado à textura arenosa indicando menor capacidade de retenção de água e menor quantidade de calcário a ser aplicado para elevar o pH (PREZOTTI; GUARÇONI, 2013). Observa-se, ainda, 
que em mais de $70 \%$ das análises selecionadas, a saturação por bases apresenta-se acima de $50 \%$ e moda de $59 \%$.

As concentrações de matéria orgânica e enxofre apresentaram resultados semelhantes, com praticamente $70 \%$ dos solos com baixa concentração (Figura 2). Nesse sentido, Sobral et al. (2015) destacam que matéria orgânica é o principal reservatório de enxofre no solo.

Figura 2. Faixas de concentração e respectiva porcentagem de matéria orgânica e enxofre em solos agrícolas de Adamantina-SP.
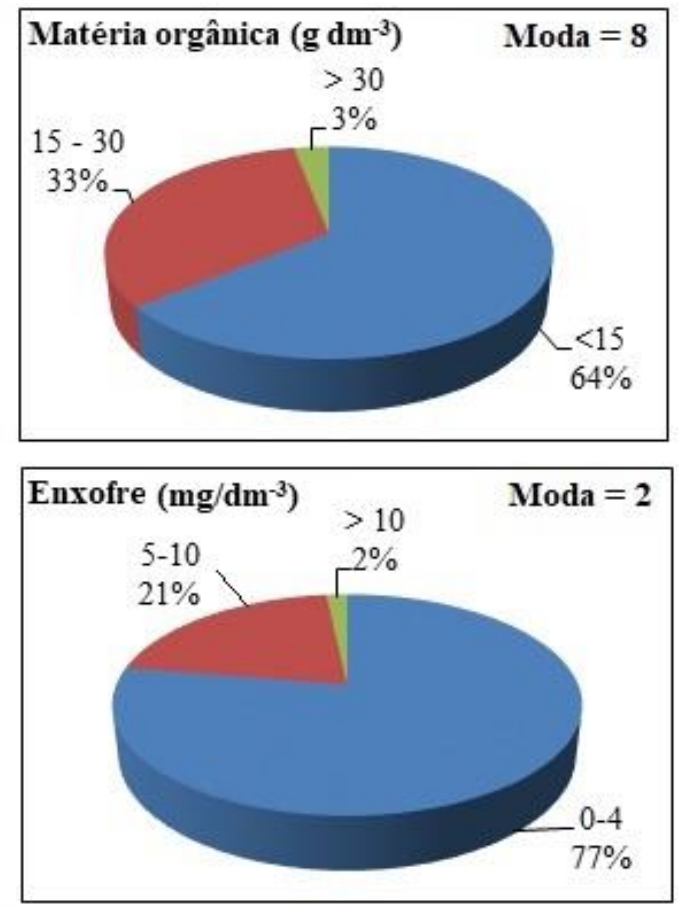

Fonte: Elaborada pelos autores, 2021.

Os resultados encontrados no presente trabalho, em amostras superficiais de 0 a $20 \mathrm{~cm}$ de profundidade, foram semelhantes aos descritos em Raij (1996) onde a matéria orgânica foi responsável por 74\% da CTC em 22 perfis de solos paulistas. O autor relatou, ainda, a matéria orgânica como possível tendência da textura do solo, e que valores até $15 \mathrm{~g} \mathrm{dm}^{-3}$ indicam solos arenosos e entre 16 e $30 \mathrm{~g} \mathrm{dm}^{-3}$ solos de textura média. Assim, os solos de AdamantinaSP são, em sua maioria, arenosos. Na Paraíba, em condições tropicais, Chaves et al. (2006) encontraram valores médios de 12,7; e moda de 18,4 $\mathrm{g} \mathrm{dm}^{-3}$, sendo estes superiores aos resultados da atual pesquisa. 
Uma das principais ações de melhoria na fertilidade do solo da região da Nova Alta Paulista é a adição constante de matéria orgânica via adubação e uso de plantio direto para complexar o $\mathrm{Al}^{3+}$ e elevar $\mathrm{pH}$ através das moléculas orgânicas liberadas, aumentando a estabilidade dos agregados do solo, o carbono orgânico total, e a diversidade de populações microbianas. Essas práticas, também, contribuem para amenizar a lixiviação de nutrientes e amplitude térmica do solo, evitando a rápida decomposição da matéria orgânica presente no solo (PREZOTTI; GUARÇONI, 2013; KOSTERNA, 2014; ROSSI et al., 2015).

Chavez et al. (2019) relataram, ainda, que a única substância orgânica que consegue influenciar as propriedades químicas do solo é o húmus. Já a palhada, apresenta maior atividade sobre a física do solo quando aplicada na superfície do solo. Dessa forma, o manejo adequado da matéria orgânica torna-se viável agronomicamente.

A baixa concentração de enxofre constatado nos laudos de fertilidade do solo de Adamantina-SP pode ser explicada pelo uso de fertilizantes sintéticos altamente concentrados, tais como ureia (fonte de $\mathrm{N}$ ), superfosfato triplo e fosfato monoamônico (fonte de $\mathrm{P}$ ), que não carregam $\mathrm{S}$ em sua formulação, além do baixo emprego de agroquímicos a base de $\mathrm{S}$ para controlar pragas e doenças nas plantas.

Nesse sentido, além da utilização de adubos orgânicos, outras fontes tradicionais de $\mathrm{N}$ e P podem ser aplicadas ao solo e que são excelentes fontes de $\mathrm{S}$, como sulfato de amônio $\left(\left(\mathrm{NH}_{4}\right)_{2} \mathrm{SO}_{4}\right)$, com 23 a $24 \%$ de $\mathrm{S}$ solúvel em água, pouco higroscópico e na forma cristalizada; superfosfato simples $\left(\left(\mathrm{Ca}\left(\mathrm{H}_{2} \mathrm{PO}_{4}\right)_{2}+\mathrm{CaSO}_{4} \cdot 2 \mathrm{H}_{2} \mathrm{O}\right)\right.$, com $12 \%$ de $\mathrm{S}$; e gesso agrícola $\left(\mathrm{CaSO}_{4} \cdot 2 \mathrm{H}_{2} \mathrm{O}\right)$, com 15 a $18 \%$ de $\mathrm{S}$ (VITTI; HEINRICHS, 2007). O gesso, que é subproduto da indústria de fertilizantes fosfatados, atua na correção da toxidez por Al e promove aumento nas concentrações de cálcio em profundidade otimizando a fertilidade do solo para culturas de alta produtividade.

Analisando o fósforo extraído por resina nos solos cultivados (Figura 3), nota-se que, conforme a planta apresenta sistema radicular mais raso, mais impactante e necessário será o fornecimento desse nutriente. Nesse sentido, as hortaliças são mais exigentes em fósforo e, aproximadamente, $10 \%$ dos solos de Adamantina-SP apresentaram concentrações acima de 60 $\mathrm{mg} \mathrm{dm}{ }^{-3}$ para esse tipo de cultivo. O baixo conteúdo de $\mathrm{P}$ (Figura 3) provavelmente deve-se à sua fixação de forma significativa em óxidos de alumínio e ferro nos solos tropicais e o baixo $\mathrm{pH}$. 
Figura 3. Faixas de concentração e respectiva porcentagem de fósforo conforme o tipo de cultura em solos agrícolas de Adamantina-SP.
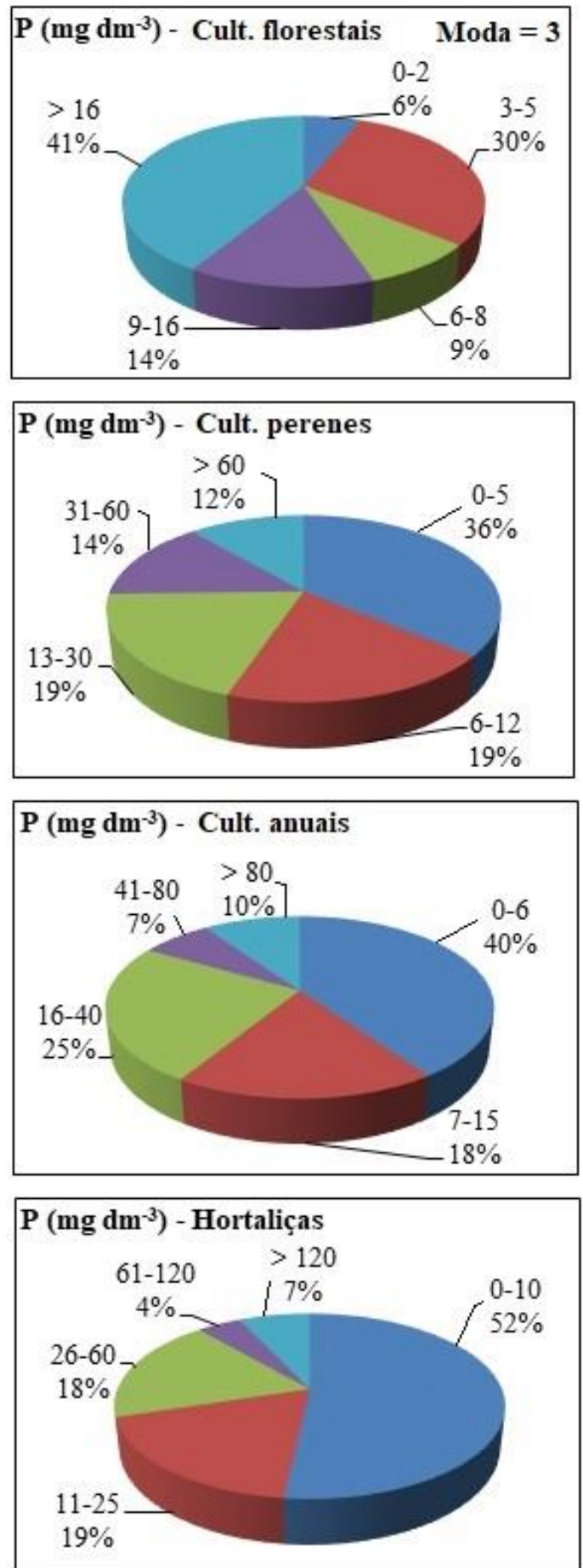

Fonte: Elaborada pelos autores, 2021.

No município de Sousa-PB, Meneses et al. (2020) encontraram valores muito superiores de fósforo para solos utilizados por comunidades agrícolas. Torna-se relevante enfatizar a análise química realizada de forma regional como ferramenta indicadora de 
fertilidade do solo para cada cultura agronômica, pois essas interpretações podem ser diferentes e menos generalizadas.

Prezotti e Guarçoni (2013) utilizando o extrator Mehlich-1, concluíram que P > 80 mg $\mathrm{dm}^{-3}$ seria a faixa de concentração adequada para a maioria das culturas localizadas no estado do Espírito Santo. Sobral et al. (2015) indicaram que para solos arenosos, o P > $20 \mathrm{mg} \mathrm{dm}^{-3}$ extraído por Mehlich-1, estaria com concentração adequada, em solos de Sergipe.

Na região da Nova Alta Paulista, torna-se obrigatório a fertilização de fósforo no solo, podendo-se optar por diferentes fontes, tanto solúveis como superfosfato simples, e menos solúveis como os fertilizantes orgânicos e termofosfatos. Neste aspecto, fertilizantes como termofosfatos, que contêm $\mathrm{Ca}, \mathrm{Mg}$, micronutrientes e silício $(\mathrm{Si})$ na forma $\mathrm{SiO}_{2}$, são indicados por agir na absorção de $\mathrm{P}$ e promover aumento de $\mathrm{pH}$ do solo por estar na forma $\mathrm{CaSiO}_{3}$ ou silicato de cálcio (GALINDO-LOPEZ et al., 2018).

Machado e Souza (2012) enfatizaram, também, que é primordial buscar informações sobre a eficiência dos fertilizantes. De acordo com os autores, pesquisas apontaram que o mono fosfatado MAP de liberação controlada, em solo arenoso, não interferiu na disponibilidade do $\mathrm{P}$, sendo a liberação máxima do nutriente aos 30 dias e queda após esse período.

Encontrou-se concentrações de potássio acima da média em mais de $70 \%$ das análises químicas (Figura 4), apesar deste elemento sofrer lixiviação em solos tropicais. Acredita-se que tal fato deve-se ao hábito do uso desse nutriente na implantação e condução das culturas como o milho, bem como na formação dos frutos em culturas perenes e frutíferas. 
Figura 4. Faixas de concentração e respectiva porcentagem de potássio, cálcio e magnésio em solos agrícolas de Adamantina-SP.
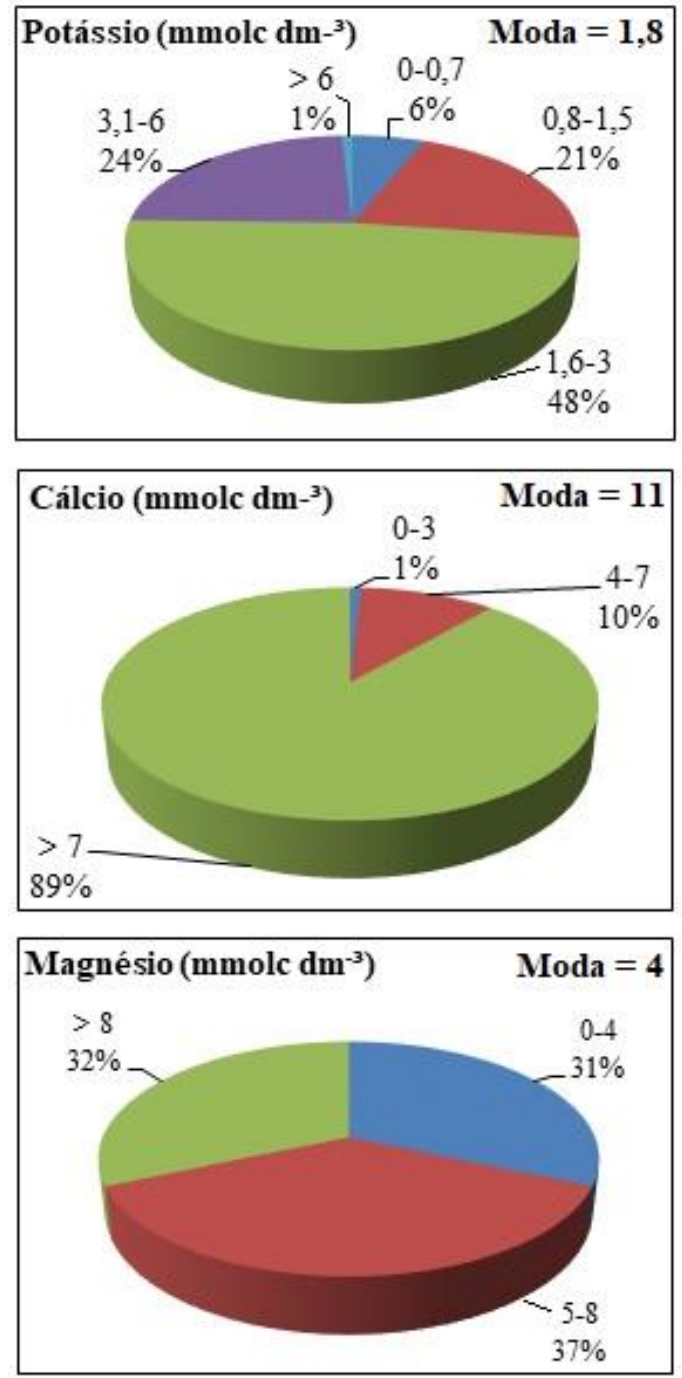

Fonte: Elaborada pelos autores, 2021.

Ressalta-se que a aplicação de potássio, muitas vezes sem critério, pode causar excesso no solo, induzir a deficiência de magnésio disponível e, também, ocasionar aumento de cálcio na solução do solo, o que pode ter levado ao resultado da moda de 4 mmolc $\mathrm{dm}^{-3}$ do magnésio. Identificou-se, ainda, que o magnésio, em aproximadamente $70 \%$ das amostras, estava com concentrações médias e altas. Associado aos valores de saturação por bases (Figura 1) e à concentração de cálcio (Figura 4), possivelmente, os solos receberam calcário.

Convém relatar que o uso de esterco de galinha é usual na região pela facilidade de aquisição em municípios adjacentes. Segundo Fernandes et al. (2013), que analisaram esterco de galinha por 5 anos em solos cultivados com cafeeiro, observaram concentrações de cálcio 8 vezes maior que potássio, e 11 vezes maior que magnésio. No entanto, as altas doses não 
interferiram no pH, V\% e matéria orgânica (Figuras 1 e 2). Esse tipo de adubo orgânico pode ter contribuído para alta concentração de cálcio em praticamente $90 \%$ das análises (Figura 4).

Quanto aos micronutrientes catiônicos e de natureza metálica (Figura 5), não há preocupação com o ferro visto que naturalmente os solos tropicais já possuem o suficiente para o cultivo, sendo que o $\mathrm{pH}$ mais baixo aumenta sua disponibilidade no solo. Contudo, como a prática de calagem eleva o $\mathrm{pH}$ e diminui a presença desse nutriente no solo, foi observado baixos valores de concentração em 47\% das análises (Figura 5).

Figura 5. Faixas de concentração e respectiva porcentagem de ferro, manganês, cobre e zinco em solos agrícolas de Adamantina-SP.
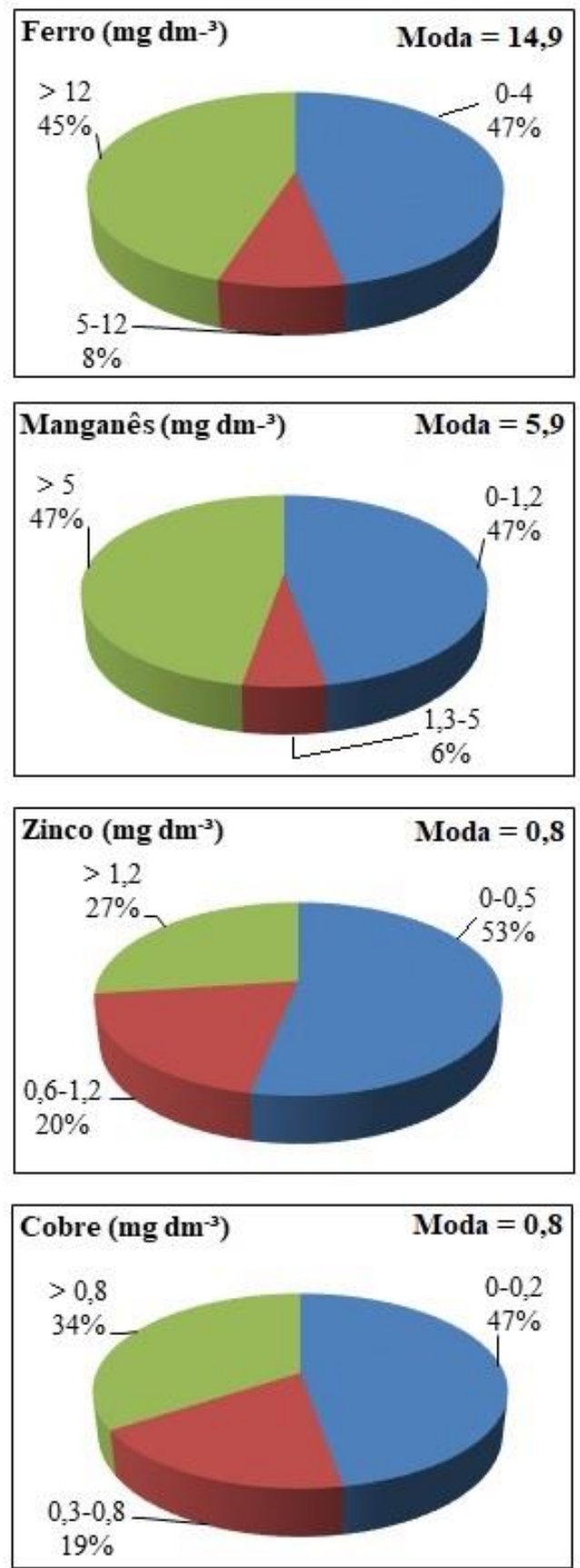

Fonte: Elaborada pelos autores, 2021. 
O manganês apresentou comportamento semelhante ao ferro, sendo muito influenciado pelo potencial hidrogeniônico do solo. A absorção desse micronutriente diminui conforme eleva-se o $\mathrm{pH}$, pois ocorre formação de óxido e hidróxidos de manganês com baixa solubilidade (OLIVEIRA JUNIOR et al., 2000).

O zinco e o cobre apresentaram $0,8 \mathrm{mg} \mathrm{dm}^{-3}$ como o valor que mais se repetiu interpretado na classe de concentração média. Esses micronutrientes são mais utilizados em adubações foliares ou misturados com fertilizantes de solo como os termofosfatos. Nota-se que zinco e cobre estão com concentrações reduzidas em $50 \%$ dos solos, e, apesar de serem necessários em baixas doses, são essenciais para cultivos de alta produtividade. De modo geral, apesar dos poucos estudos em micronutrientes quando comparado aos macronutrientes (SOUSA et al., 2011), deficiências podem aparecer pela elevação de $\mathrm{pH}$ quando ocorre excesso de calagem (ASSMANN et al., 2017).

O boro apresentou níveis baixos em $86 \%$ dos solos amostrados e moda de $0,11 \mathrm{mg} \mathrm{dm}^{-}$ 3 (Figura 6) mostrando deficiência significativa de boro em solos tropicais, fato ligado normalmente a solos ácidos, arenosos e com baixa matéria orgânica (BERGAMIN et al., 2005).

A baixa disponibilidade do boro também pode ocorrer pela maior utilização de fontes solúveis de boro, como ácido bórico, que apresentam alta mobilidade no solo, favorecendo a lixiviação em solos arenosos. Nesse aspecto, Oldoni et al. (2018) concluíram que a hidroboracita pode ser utilizada como fonte de boro com alta disponibilidade residual e baixa perda por lixiviação.

Figura 6. Faixas de concentração e respectiva porcentagem de boro em solos agrícolas de Adamantina-SP.

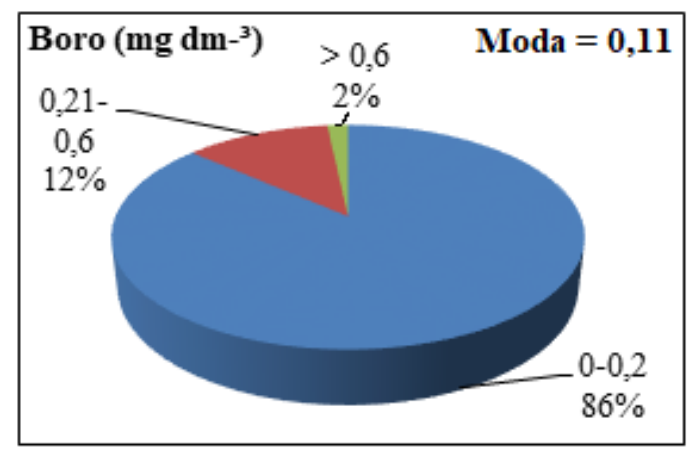

Fonte: Elaborada pelos autores, 2021. 


\section{CONCLUSÃO}

Os solos de Adamantina-SP, de modo geral, recebem calagem, fertilizantes a base de macronutrientes e, em alguns casos, adubo orgânico de baixa permanência no solo, que influenciam diretamente na capacidade de troca catiônica e disponibilidade de $\mathrm{P}, \mathrm{S}$ e B que apresentaram níveis reduzidos nos solos avaliados no estudo.

\section{REFERÊNCIAS}

ASSMANN, J. M. et al. Phosphorus and potassium cycling in a long term no till integrated soybean beef cattle production system under different grazing intensities in subtropics. Nutrient Cycling in Agroecosystems, v.108, p.21-33, 2017. Disponível em: https://doi.org/10.1007/s10705-016-9818-6. Acesso em: 05 jan. 2021.

BERGAMIN, L. G. et al. Produção de repolho em função da aplicação de boro associada à adubo orgânico. Horticultura Brasileira, v.23, n.2, p.311-315, 2005. Disponível em: https://doi.org/10.1590/S0102-05362005000200030. Acesso em: 12 dez. 2020.

BOIN, M. N. Chuvas e erosões no oeste paulista: uma análise climatológica aplicada. 2000. 264f. Tese (Doutorado em Geociências e Meio Ambiente) - UNESP/Rio Claro, 2000.

CHAVES, L. H. G. et al. Propriedades químicas dos solos da bacia hidrográfica do açude Namorado, PB. Revista Principia, n.14, p.68-75, 2006. Disponível em: http://dx.doi.org/10.18265/1517-03062015v1n14p68-75. Acesso em: 08 dez. 2020.

CHAVEZ, P. C. et al. Fertilización organomineral en el manejo sostenible de tierras cultivadas con maíz. Revista Científica Agroecosistemas, v.7, p.116-122, 2019. Disponível em: https://aes.ucf.edu.cu/index.php/aes/article/view/325. Acesso em: 11 dez. 2021.

FERNANDES, A. L. T. et al. Adubação orgânica do cafeeiro, com uso do esterco de galinha, em substituição à adubação mineral. Coffee Science, v.8, n.4, p.486-499, 2013. Disponível em: https://www.researchgate.net/publication/261287782. Acesso em: 02 jan. 2021.

FREITAS, L. et al. Indicadores da qualidade química e física do solo sob diferentes sistemas de manejo. Revista Unimar Ciências, v.26, n.1, 2017. Disponível em:

http://ojs.unimar.br/index.php/ciencias/article/view/511. Acesso em: 28 dez. 2020.

GALINDO-LOPEZ, F. et al. Evaluación de un termofosfato en el crecimiento y producción de fresa. Revista Universidad de Ciencias Aplicadas y Ambientales, v.21, n.1, p.61-69, 2018. Disponível em: https://doi.org/10.31910/rudca.v21.n1.2018.663. Acesso em: 20 dez. 2020.

GIARETTA, J. et al. Avanço da atividade agropecuária sobre as áreas de vegetação natural na capital nacional do agronegócio. Ambiente \& Sociedade, v.22, p.1-22, 2019. Disponível em: https://www.scielo.br/pdf/asoc/v22/pt_1809-4422-asoc-22-e01392.pdf. Acesso em: 03 dez. 2020. 
KOSTERNA, E. Soil mulching with straw in broccoli cultivation for early harvest. Journal of Ecological Engineering, v.15, n.2, p.100-107, 2014. Disponível em: https://doi.org/10.12911/22998993.1094985. Acesso em: 15 nov. 2020.

LSPA. Levantamento Sistemático da Produção Agrícola. Área plantada, área colhida, quantidade produzida e rendimento médio de produtos. Rio de Janeiro: IBGE, 2020. Disponível em: https://www.ibge.gov.br/estatisticas/economicas/agricultura-e-pecuaria.html. Acesso em: 17 dez. 2020.

MACHADO, V. J.; SOUZA, C. H. E. Disponibilidade de fósforo em solos com diferentes texturas após aplicação de doses crescentes de fosfato monoamônico de liberação lenta.

Bioscience Journal, v.28, supl.1, p.1-7, 2012. Disponível em: https://docs.bvsalud.org/biblioref/2018/09/912072/disponibilidade-de-fosforo-em-solos-comdiferentes-texturas.pdf. Acesso em: 28 nov. 2020.

MENESES, M. G. et al. Caracterização do solo em comunidades agrícolas no município de Sousa para fins de produtividade. Revista Principia, n.48, p.112-118, 2020. Disponível em: http://dx.doi.org/10.18265/1517-03062015v1n48p112-118. Acesso em: 16 dez. 2020.

OLDONI, F. C. A. et al. Manejo da adubação com boro na produção e qualidade dos frutos da manga cv. Palmer no semiárido. Revista Brasileira de Fruticultura, v.40, n.3, p.1-8, 2018. Disponível em: https://doi.org/10.1590/0100-29452018622. Acesso em: 21 nov. 2020.

OLIVEIRA JUNIOR, J. A. et al. Efeitos do manganês sobre a soja cultivada em solo de cerrado do Triângulo Mineiro. Pesquisa Agropecuária Brasileira, v.35, n.8, p.1629-1636, 2000. Disponível em: https://doi.org/10.1590/S0100-204X2000000800016. Acesso em: 10 dez. 2020.

PREZOTTI, L. C.; GUARÇONI, A. Guia de interpretação de análise de solo e foliar. Vitória: INCAPER, 2013. 104p.

RAIJ, B. VAN. et al. Recomendações de adubação e calagem para o Estado de São Paulo. 2. ed. Campinas: Instituto Agronômico de Campinas, 1996. 280p. (Boletim Técnico IAC, 100).

RODRIGUES, T. et al. Mapeamento da vulnerabilidade aos processos erosivos a partir de métodos multicriteriais. Revista Formação, v.25, n.45, p. 67-91, 2018. Disponível em: https://revista.fct.unesp.br/index.php/formacao/article/view/5310. Acesso em: 19 dez. 2020.

ROSSI, C. Q. et al. Atributos químicos e físicos de solo cultivado com oleráceas em microbacia hidrográfica após desastre ambiental. Revista Brasileira de Ciência do Solo, v.39, n.6, p.1764-1775, 2015. Disponível em:

https://doi.org/10.1590/01000683rbcs20140253. Acesso em: 05 dez. 2020.

SOBRAL, L. F. et al. Guia prático para interpretação de resultados de análise de solo. Embrapa Tabuleiros Costeiros: Aracaju, 2015, 13p. (Documento, 206).

SOUSA, G. G. et al. Crescimento de mudas de maracujazeiro em função de adubação à base de boro e material de cupinzeiro. Pesquisa Agropecuária Tropical, v.41, n.2, p.170-178, 2011. Disponível em: https://www.scielo.br/pdf/pat/v41n2/a04.pdf. Acesso em: 24 nov. 2020. 
TEIXEIRA, P. C. et al. Manual de métodos de análise de solo. 3. ed. Brasília, DF: Embrapa, 2017. 573p.

VIEIRA, D. M. S. et al. Cultivo de vegetais em sucessão em diferentes solos e doses de fósforo em fertilizante organomineral. Revista Brasileira de Engenharia Agrícola e Ambiental, v.24, n.12, p.806-813, 2020. Disponível em: https://doi.org/10.1590/18071929/agriambi.v24n12p806-813. Acesso em: 02 jan. 2021.

VITTI, G. C.; HEINRICHS, R. Formas tradicionais e alternativas de obtenção e utilização do nitrogênio e do enxofre. In: YAMADA, T.; STIPP, A.R.; VITTI, G.C. Nitrogênio e enxofre na agricultura brasileira. Piracicaba: IPNI Brasil, p.109-160, 2007. 